\title{
Disease-associated metabolic alterations that impact satellite cells and muscle regeneration: perspectives and therapeutic outlook
}

\author{
Josiane Joseph ${ }^{1}$ and Jason D. Doles ${ }^{2^{*}}$ (]
}

\begin{abstract}
Many chronic disease patients experience a concurrent loss of lean muscle mass. Skeletal muscle is a dynamic tissue maintained by continuous protein turnover and progenitor cell activity. Muscle stem cells, or satellite cells, differentiate (by a process called myogenesis) and fuse to repair and regenerate muscle. During myogenesis, satellite cells undergo extensive metabolic alterations; therefore, pathologies characterized by metabolic derangements have the potential to impair myogenesis, and consequently exacerbate skeletal muscle wasting. How disease-associated metabolic disruptions in satellite cells might be contributing to wasting is an important question that is largely neglected. With this review we highlight the impact of various metabolic disruptions in disease on myogenesis and skeletal muscle regeneration. We also discuss metabolic therapies with the potential to improve myogenesis, skeletal muscle regeneration, and ultimately muscle mass.
\end{abstract}

Keywords: Atrophy, Degeneration, Metabolism, Muscle wasting, Myoblasts, Satellite cells

\section{Introduction}

Skeletal muscle is a vital organ that supports locomotion, respiration, vision, and posture. Additionally, skeletal muscle significantly contributes to organismal physiology through energy production and endocrine signaling [1,2]. To accommodate these and other daily activities, skeletal muscle cells can increase or decrease mitochondrial biomass [3]. Adjustments to protein content and enzymatic activity in muscle also supports normal function. As a consequence of many chronic diseases-such as Huntington's Disease [4], chronic kidney disease [5], various cancers [6, 7], lung pathologies

*Correspondence: doles.jason@mayo.edu

2 Department of Biochemistry and Molecular Biology, Mayo Clinic, 200 First St SW, Rochester, MN 55905, USA

Full list of author information is available at the end of the article
[8], and myopathies-abnormal shifts in skeletal muscle metabolism frequently arise.

In addition to disruptions in cellular metabolism, many chronic diseases are often associated with significant skeletal muscle wasting. Muscle wasting results in unfavorable loss of functional capacity and quality of life in affected individuals. Despite substantial basic and clinical work to understand and address this prevalent issue, there are no consistently successful therapies to resolve muscle wasting. These limitations suggest that our current approach towards the issue of muscle wasting should be refocused. Skeletal muscle mass is maintained by a balance of protein anabolism, protein catabolism, and cellular turnover. Though muscle atrophy is primarily attributed to increased protein degradation without compensated protein production $[9,10]$, some recent evidence suggests that impaired regeneration may also play a role [11]. Muscle repair original author(s) and the source, provide a link to the Creative Commons licence, and indicate if changes were made. The images or other third party material in this article are included in the article's Creative Commons licence, unless indicated otherwise in a credit line to the material. If material is not included in the article's Creative Commons licence and your intended use is not permitted by statutory regulation or exceeds the permitted use, you will need to obtain permission directly from the copyright holder. To view a copy of this licence, visit http://creativecommons.org/licenses/by/4.0/. The Creative Commons Public Domain Dedication waiver (http://creativeco mmons.org/publicdomain/zero/1.0/) applies to the data made available in this article, unless otherwise stated in a credit line to the data. 
involves necrosis of injured tissues, invasion of leukocytes, clearance by phagocytic cells, scarring, revascularization, fusion of muscle progenitor cells, and remodeling to restore functional capacity of the muscle [12]. Indeed, a diverse community of cells is required to regenerate muscle after it is damaged by normal use or injury.

The functional adult muscle progenitor cell is the satellite cell. These cells are located between the sarcolemma and basement membrane of muscle fibers and are frequently adjacent to blood vessels [13, 14]. Satellite cells are stimulated under stress to proliferate, differentiate, and fuse into muscle fibers by a process called myogenesis [15]. In addition to contributing new nuclei and cellular material to terminally differentiated myofibers, satellite cells must replenish the quiescent reserve of satellite cells for subsequent muscle repair, in a process termed self-renewal. With all of the events that must occur in sequence in order for skeletal muscle to successfully regenerate, there are multiple avenues for pathological disruption.

While quiescent, satellite cells primarily utilize fatty acid and pyruvate oxidation to meet energetic demands but switch to aerobic glycolysis when activated [16]. After activation satellite cells divide asymmetrically. This expansion is synced with mitochondrial biogenesis [17]. As they differentiate, myoblasts (or activated satellite cells) increase mitochondrial biomass in favor of oxidative phosphorylation $[18,19]$. To accommodate the metabolic adjustments that occur during each phase of myogenesis, functional autophagy programs are required [20]. Thus, factors that impair autophagy have the potential to undermine skeletal muscle repair. With this review we highlight several disease-associated metabolic disruptions that alter satellite cell function and impact skeletal muscle regeneration and emphasize potential avenues for future investigation. Additionally, we discuss metabolic interventions reported to boost satellite cell function and/or skeletal muscle regeneration.

\section{Metabolic disruptions in disease that impact skeletal muscle regeneration}

Skeletal muscle is a highly metabolic tissue and muscle regeneration capacity is dependent on multiple variables. For example, satellite cell quantity, activation and proliferation, myogenesis, and fusion all contribute to skeletal muscle regeneration. Pathologies that directly alter muscle metabolic activity or that systemically affect cellular metabolism-such as obesity, diabetes, aging, neuromuscular disorders, and sepsis-influence the ability of satellite cells to function in their primary role of regenerating muscle (Table 1).

\section{Obesity}

In the context of obesity, adipose tissue accumulates in muscle where it can secrete compounds that influence neighboring cells. Lipids are known modulators of satellite cell function [21, 22]. Lipoprotein lipase (LPL) aids in lipid catabolism for cellular uptake [23] and these hydrophobic molecules may accumulate and alter cell function. For example, lipid overload (cause by LPL overexpression) can inhibit early myogenesis, impair satellite cell proliferation, and reduce regeneration capacity [11]. The overall depletion of lean mass observed in obese individuals [24] may partially be attributable to ineffective satellite cell activity. In line with this prediction, $\operatorname{MCK}(\mathrm{m})$-hLPL mice with elevated lipids, specifically in striated muscle, have reduced type II muscle weights when compared to wildtype controls [11]. Inflammation and insulin resistance are also traits of obesity that may negatively influence muscle mass; however, that does not negate the potential role of satellite cell metabolic dysfunction in muscle wasting.

\section{Diabetes}

Though the pathogenesis of type I and type II diabetes is distinct, they are similarly characterized by elevated blood glucose. Interestingly, individuals with type I diabetes mellitus have fewer satellite cells than healthy controls [25]. Additionally, satellite cells from a type I diabetic environment exhibit impaired activation and self-renewal capacity [25]. Again these differences were observed concurrently with a reduction in muscle weight suggesting an association [25]. While the former study did not assay regeneration, another group recently determined that myogenesis is hindered in mice with impaired fasting glucose and glucose tolerance [26]. Though multiple studies have identified muscle wasting in diabetic models, the cause of the muscle loss is uncertain [27, 28]; what is becoming clear is that satellite cells are defective in this disease.

\section{Aging}

As age increases, tissue regenerative capacity decreases. There are physiological changes that occur with agesuch as declines in sex hormones-that are related to reduced muscle mass and modified cellular compartments. Several investigators reported that satellite cell quantity [29] and function remains fairly constant with age [30], while others showed age-associated satellite cell depletion [31] and diminished self-renewal capacity [32]. Despite this discordance, what is clear is that aged satellite cells have altered metabolic profiles and likely use alternate carbon sources for energy production [33]. Additionally, glycolytic enzymes have an increased 
Table 1 Pathologies associated with altered cellular metabolism and satellite cell dysfunction

\begin{tabular}{|c|c|c|c|}
\hline Investigators & Model & Metabolic disturbance(s) & Outcome \\
\hline Tamilarasan et al. [11] & MCK(m)-hLPL mice & $\begin{array}{l}\text { Striated muscle targeted elevation of } \\
\text { lipids }\end{array}$ & $\begin{array}{l}\text { Reduced muscle weight and cross- } \\
\text { sectional area (or regeneration) after } \\
\text { injury }\end{array}$ \\
\hline Tamilarasan et al. [11] & hLPL transfected $\mathrm{C} 2 \mathrm{C} 12$ myoblasts & Elevated intracellular FFA & $\begin{array}{l}\text { Impaired myoblasts fusion and myo- } \\
\text { genesis }\end{array}$ \\
\hline Fu et al. [86] & High-fat diet fed mice & Obesity & $\begin{array}{l}\text { Reduced muscle regeneration and } \\
\text { reduced primary satellite cell pool }\end{array}$ \\
\hline D'Souza et al. [25] & C57BL/6-Ins $2^{\text {Akita/J }}$ mice & Type I diabetes & $\begin{array}{l}\text { Reduced muscle weight } \\
\text { Reduced satellite cell activation and } \\
\text { proliferation } \\
\text { Reduced myogenic transcripts }\end{array}$ \\
\hline Xu et al. [26] & 16 week High-Fat Diet fed mice & Pre-diabetes/Obesity & $\begin{array}{l}\text { Impaired primary satellite cell differen- } \\
\text { tiation }\end{array}$ \\
\hline García-Prat et al. [36] & GFP-LC3 Geriatric mice & Advanced age/Senescence & $\begin{array}{l}\text { Impaired satellite cell autophagy } \\
\text { Impaired expansion and fusion of trans- } \\
\text { planted myoblasts }\end{array}$ \\
\hline García-Prat et al. [36] & Human primary myoblasts & Advanced age/Senescence & $\begin{array}{l}\text { Impaired clearance of cellular compo- } \\
\text { nents and increased ROS } \\
\text { Reduction in proliferation }\end{array}$ \\
\hline Servián-Morilla et al. [37] & $\begin{array}{l}\text { Limb-girdle muscular dystrophy } 2 \mathrm{H} \\
\text { patients }\end{array}$ & $\begin{array}{l}\text { Premature senescence } \\
\text { Fatty replacement of muscle }\end{array}$ & $\begin{array}{l}\text { Reduced myoblast proliferation and } \\
\text { differentiation } \\
\text { Increased autophagic flux in myoblast }\end{array}$ \\
\hline Kudryashova et al. [38] & Trim32 $2^{-/-}$(Limb-girdle dystrophy) mice & Premature senescence & $\begin{array}{l}\text { Myoblast growth arrest } \\
\text { Impaired myoblasts self-renewal and } \\
\text { differentiation }\end{array}$ \\
\hline $\begin{array}{l}\text { Yablonka-Reuveni et al } \\
\text { Bell et al }\end{array}$ & mdx mice & Mitochondrial abnormalities [47] & Accelerated muscle regeneration [42] \\
\hline Schaaf et al. [48] & $\begin{array}{l}\text { Pompe patients } \\
\text { (4 disease groups) }\end{array}$ & Lysosomal glycogen accumulation & $\begin{array}{l}\text { Impaired satellite cell activation and } \\
\text { differentiation }\end{array}$ \\
\hline Lagalice et al. [49] & GAA-KO $6^{\text {neo }} / 6^{\text {neo }}($ Pompe) mice & $\begin{array}{l}\text { Lysosomal glycogen accumulation } \\
\text { Lipid accumulation }\end{array}$ & $\begin{array}{l}\text { Impaired muscle regeneration } \\
\text { Increase satellite cell activation (and } \\
\text { quantity for young mice only) }\end{array}$ \\
\hline Schaaf et al. [50] & $\mathrm{Gaa}^{-/-}$(Pompe) mice & Lysosomal glycogen accumulation & $\begin{array}{l}\text { Increased satellite cell pool } \\
\text { Impaired muscle regeneration }\end{array}$ \\
\hline Manzano et al. [55] & SOD1-G93A mutant (ALS) mice & Altered superoxide dismutase function & $\begin{array}{l}\text { Alterations in satellite cell abundance } \\
\text { and activation }\end{array}$ \\
\hline Gouzi et al. [8] & COPD patients & Elevated ROS & Increased myoblast autophagy \\
\hline Pomiès et al. [63] & COPD patients & Increased oxidative stress & $\begin{array}{l}\text { Myoblasts with: greater susceptibility to } \\
\text { oxidative stress, reduced fusion capa- } \\
\text { ity, increased protein carbonylation } \\
\text { Myotubes with reduced diameter }\end{array}$ \\
\hline Rocheteau et al. [64] & Cecal ligation and puncture in mice & Sepsis & $\begin{array}{l}\text { Impaired satellite cell proliferation } \\
\text { Reduced satellite cell quantity } \\
\text { Impaired muscle regeneration } \\
\text { Altered satellite cell mitochondria }\end{array}$ \\
\hline
\end{tabular}

incidence of oxidation in senescent human myoblasts [33] which may play a role in the impaired regeneration and function of muscle observed in geriatric cohorts [34, 35]. Furthermore, autophagy function is frequently defective which begets a loss of satellite cell stemness in aged individuals [36]. As autophagy is also required for mitochondrial turnover (a process pertinent to satellite cell differentiation) [20] more effort should be made to decipher if the loss of skeletal muscle regeneration observed in aged individuals could be prescribed, to some degree, to satellite cell metabolic disruption.

\section{Myopathies and neuromuscular disorders}

Skeletal muscle wasting occurs in metabolic disorders (such as Pompe disease) or may arise as a consequence of other factors that lead to altered metabolism in muscle. For example ALS is considered to be a neuronal pathology, however, as the disease progresses skeletal muscle 
wasting and metabolic defects are noted. Though the mechanisms by which neighboring tissues or pathologies achieve metabolic disruptions in muscle are unclear, there is abundant evidence that satellite cells are altered and regeneration may be impaired in a multitude of diseases.

As in aging, senescent satellite cells with dysfunctional metabolism are typical of a limb-girdle myopathy caused by mutated TRIM32. In this myopathy, myogenesis is impaired and overall there are fewer activated muscle stem cells [37, 38]. Satellite cells from TRIM32 mutated limb-girdle myopathy patients are characterized by abnormal autophagy activity and an accumulation of TRIM32 substrates [37]. TRIM32 regulates p62 activity and p62 targets other proteins for selective autophagy [39]. This disruption in autophagy may have implications for myogenesis and there is opportunity to understand how satellite cells may contribute to muscle wasting in individuals with this form of myopathy.

Dystrophin, the gene mutated in Duchenne muscular dystrophy, is substantially expressed in satellite cells [40]. Loss of dystrophin in satellite cells results in defective asymmetric cellular divisions and increased activation and is also associated with impaired muscle regeneration [40,41]. Interestingly, despite the gradual loss of skeletal muscle mass in muscular dystrophy, dystrophic myoblasts exhibit accelerated differentiation [42]. This hyperactivity may contribute to the exhaustion of satellite cells which is suspected to lead to the severe deterioration of muscle $[43,44]$. Although dystrophic satellite cells are defective they retain their ability to regenerate muscle fibers when transplanted to a wildtype host [45], indicating that the metabolically altered disease environment is a significant contributor to regenerative dysfunction. Dystrophic satellite cells are known to have distinct metabolic profiles when compared to cells from healthy controls [46]. Satellite cells from dystrophic mice also have fewer mitochondria, produce less ATP, are less susceptible to ATP synthase inhibition, and have reduced oxygen consumption rates [47]. Various metabolic defects in dystrophic satellite cells may play a role in the progressive muscle loss observed in Duchenne muscular dystrophy.

Pompe disease is caused by acid a-glucosidase deficiency. The resulting accumulation of glycogen in lysosomes causes loss of striation and vacuolization of muscle along with infiltration of leukocytes. The process of autophagy depends on functional lysosomes and as observed above satellite cells utilize autophagy for progression of myogenesis. Though the quantity and expansion of satellite cells in patients with Pompe disease is similar to healthy controls, satellite cell activation and muscle regeneration is impaired [48]. In mice, similar findings were reported with the additional observation of larger pools of satellite cells present in the muscle of younger mice $[49,50]$. The impaired autophagy characteristic of lysosomal storage diseases [51-53] and reduced cross-sectional area of muscle myofibers in animal models of Pompe disease $[49,50]$ further supports the premise that satellite cell dysfunction may contribute to muscle wasting in this disorder.

A common cause of familial amyotrophic lateral sclerosis (ALS) is the mutation of a superoxide dismutase. Though the pathophysiology of ALS is unclear, skeletal muscle metabolic irregularities are suspected to contribute [54]. In this disease, satellite cells have variable abundance and capacity for activation depending on disease stage [55]. Additionally, satellite cells from ALS patients have morphologic features indicative of senescent cells and express senescence markers [56]. As previously discussed, senescent satellite cells have defective autophagy programs that preclude effective myogenesis. Altogether these data support our need to understand how skeletal muscle regeneration failure could be implicated in the muscle loss typical of this disease.

\section{Chronic obstructive pulmonary disease}

For COPD patients, multiple variables may contribute to the skeletal muscle dysfunction often associated with disease including age, obesity, level of physical activity, prescribed steroids, tobacco use, systemic inflammation and reactive oxygen species [57]. Regulated shifts in reactive oxygen species (ROS) are associated with mitochondrial biogenesis and myogenic differentiation [58-61]. Myoblasts from patients with COPD appear to have increased autophagy accompanied by elevated reactive oxygen species [8]. These findings are consistent with other reports of satellite cells from COPD patients bearing features of senescent cells [62]. Though proliferation is unaffected in myoblasts from COPD patients, these progenitor cells are more susceptible to oxidative stress and have reduced fusion capacity [63]. The satellite cell deficits documented may contribute to the muscle atrophy noted in COPD patients.

\section{Sepsis}

Sepsis physiology is characterized by impaired perfusion, inflammation, and ROS. All of these factors may play a role in the skeletal muscle wasting that is common among sepsis patients. Notably, there are fewer satellite cells with reduced capacity to regenerate muscle in individuals that have experienced sepsis [64]. Additionally, satellite cells in mice that have survived severe sepsis have reduced ROS and increased markers of oxidative stress (such as carbonylated and nitrated proteins) [64]. The alterations noted in satellite may lead to chronically impaired regeneration and futures efforts should be made 
to determine if they account for lasting muscle deficiencies observed in septic patients.

\section{Metabolic interventions that improve skeletal muscle pathology or promote muscle regeneration}

As highlighted above, various disease processes coincide with dysfunctional skeletal muscle metabolism and impaired satellite cell function. As such, skeletal muscle metabolism may be an attractive target to mitigate muscle wasting, rescue impaired regeneration, and restore muscle function. Below, we highlight recent efforts to target muscle metabolism, including nutritional or small molecule supplements, hormone replacement, reduction of ROS, behavioral modifications, dietary modifications, and other therapeutic modalities. Effects on satellite cell function and/or muscle regeneration are also discussed.

\section{Select nutritional and small molecule interventions}

Several common compounds are linked to improved muscle regeneration in diverse disease environments. A first example is acetoacetate which is a ketone body that improves skeletal muscle function and integrity in Duchenne muscle dystrophy [65]. In the dystrophic context, acetoacetate promotes muscle regeneration while improving satellite cell proliferation and differentiation [65]. Second, a flax seed rich diet also maintains muscle fiber integrity and improves regeneration in a model of dystrophic skeletal muscle [66]. A compound abundant in flaxseeds, alpha-linolenic acid, improves regeneration and reduces apoptosis of myogenic cells in vitro [66]. A third ubiquitous compound that may have regenerative benefits is nicotine. Nicotine promotes myogenesis in vitro and improves skeletal muscle regeneration in the context of obesity [67].

Other compounds that are easily purchased or commonly prescribed might be candidates to reverse muscle wasting. For example, geranylgeraniol, a molecule found in grains, fruits, and vegetables promotes myoblast differentiation and reduces the expression of proteins associated with atrophy [68]. Vitamin D (in the form of $1 \alpha$-dihydroxyvitamin D3) improves human myoblast migration in vitro and enhances myogenesis [69]. Finally, rapamycin restores autophagy in satellite cells allowing for the clearance of cytosolic components and bioenergetics transitions [36].

Reactive oxygen species are required for normal cellular function but are frequently elevated in disease. Following this logic, antioxidants such as resveratrol, ursolic acid, and ascorbic acid are commonly evaluated for their therapeutic benefits. Treating myoblasts with resveratrol results in reduced apoptosis and improved differentiation in the presence of excess reactive oxygen species [70]. Seven day treatment with ursolic acid increases satellite cell quantity and fusion into myofibers [71]. Ascorbic acid increases myofibers diameter and reduces autophagy related mechanisms in cultured patient myoblasts [8]. Individuals with mitochondrial myopathies may require reactive oxygen species signaling for optimal muscle regeneration [72]. Although current interventions often favor restriction of reactive oxygen species, for certain myopathies, loss of reactive oxygen species could exacerbate pathology. Nevertheless, therapeutic targeting of reactive oxygen species remains promising because it can be accomplished by various means including non-invasive strategies such as nutritional modification and physical activity.

\section{Hormone replacement}

Hormonal changes naturally occur with age. Growth hormone is typically reduced in subjects with advanced age, and loss of this hormone contributes to loss of muscle mass in geriatric individuals. Replacement of growth hormones improve mitochondrial biogenesis, reduce oxidative damage, increase protein synthesis, and increase factors associated with regeneration in muscle [73]. Unfortunately, growth hormone therapy is administered by regular injections, and there is no established consensus on its effectiveness at improving muscle function in humans $[74,75]$. Despite the limitations, it may be worth exploring hormonal therapies for chronic and debilitating muscular disorders.

To combat age-related declines in sex hormone levels, replacement of testosterone for men and estrogen for women might also be considered to improve muscle mass. For example, satellite cell activation and muscle regeneration is facilitated by estrogen analog injection [76]. Moreover, testosterone increases satellite cell quantity and myonuclei, and is associated with muscle hypertrophy [77]. As with many hormonal therapies, however, there are systemic side-effects to consider with either of these options.

\section{Behavioral and hyperbaric oxygen interventions}

Certain activities, such as weight training, are known to improve muscle mass. In disease, however, strenuous physical activity may not be possible. Alternatives or supplements to exercise become invaluable in such a scenario. Short-term caloric restriction increases satellite cell quantity, mitochondrial content, and proliferation and altogether contributes to muscle regeneration [78]. Improvements in satellite cell function were concurrent with an increase in oxygen consumption rate and a decrease in extracellular acidification rate [78]. Though caloric restriction appears to be beneficial in some models of myogenesis, the evidence varies with sex and by model and therefore requires further investigation [79]. 
Another proposed treatment option is hyperbaric oxygen immersion and/or inhalation. The treatment would entail breathing or immersing the body in oxygen at higher pressure in order to increase the oxygen content of tissues. Hyperbaric oxygen is already in use for non-healing wounds, decompression illness, and other indications. It is not standard therapy for muscle injury, but treatment with hyperbaric oxygen is an option to enhance muscle regeneration [80]. Hyperbaric oxygen increases satellite cell proliferation and differentiation while also facilitating macrophage invasion in damaged tissue which may explain the improvements in muscle regeneration and function observed after its use in rats [81]. Hyperbaric oxygen therapy also promotes muscle repair after injury by stimulating angiogenesis [82]. It is not clear if hyperbaric oxygen therapy can improve outcomes for chronic diseases. In Duchenne's muscular dystrophy, for example, this treatment may not be beneficial [83].

\section{Biologics}

Mesenchymal stem cell therapies are increasing in popularity and generally regulate inflammatory environments by secreting cytokines. In accord with known anti-inflammatory properties, intramuscular injection of mesenchymal stem cells reduces cytokine levels in septic mice [64]. Additionally transplanted mesenchymal stem cells improve muscle regeneration and restore mitochondrial activity in satellite cells of septic mice [64]. Intraperitoneal injections of bone marrow derived mesenchymal stem cells improves the morphology of myofibers, increase satellite cell quantity, and improves lifespan overall for Duchenne muscular dystrophy mice [84]. Two growth factors secreted by mesenchymal stem cells, CXCL12 and osteopontin, facilitate improved regeneration in dystrophic mice [84]. Despite a growing list of promising basic and preclinical mesenchymal stem cell studies, key obstacles remain. For example, stem cell-based therapies are challenging to standardize and repeated injections of a bulky and dynamic cellular product is not always favorable. Alternatively, injecting exosomes from mesenchymal stem cells may be an option. Indeed, intramuscular exosome treatment reportedly promotes angiogenesis, myogenesis, and muscle regeneration [85].

\section{Conclusions}

In general, satellite cells are often overlooked when evaluating disease associated muscle wasting which may hamper our understanding of this syndrome. One limitation of many studies that assess metabolic dysfunction and wasting of muscle includes the focus on a single muscle, typically the tibialis anterior (a hind limb muscle), and neglect of other skeletal muscle types. Another barrier is the multitude of models designed to recapitulate the multifactorial muscle wasting syndrome hampers our ability to elucidate the causes (particularly related to altered metabolism) and effective treatments. This descriptive review outlines various metabolic abnormalities in satellite cells that are associated with wasting of skeletal muscle; due to the significance of metabolic regulation in satellite cell function our work is a start to interrogating how these metabolic disruptions may be enhancing refractory muscle wasting. There are options available to treat metabolic abnormalities in satellite cells and skeletal disease as detailed in this work. Considering the lack of effective treatment in the clinical setting, an improved understanding of disease-associated metabolic changes in satellite cells and how they impact muscle regeneration represents a promising path forward to addressing pathological loss of lean mass.

\section{Abbreviations}

LPL: Lipoprotein lipase; ROS: Reactive oxygen species.

\section{Acknowledgements}

We would like to express our appreciation for the Mayo Clinic Medical Scientist Training Program, the Mayo Clinic Department of Clinical and Translational Science, and the Mayo Clinic Department of Biochemistry and Molecular Biology for fostering an exceptional academic environment.

\section{Authors' contributions}

JJ drafted the ideas presented in this work. JD offered suggestions for organization and enhancement of the article. All authors read and approved the final manuscript.

\section{Funding}

Josiane Joseph is supported by the National Institute of Health (UL1TR002377, T32GM65841, and R25GM055252) and the Corella and Bertram Bonner MD, Ph.D. Scholarship. Jason Doles is supported by the National Institute of Health (R00AR66696 and R35GM128594), the Pancreatic Cancer Action Network/ American Association of Cancer Research (17-20-25-DOLE), and the Glenn Foundation for Medical Research.

Availability of data and materials Not applicable.

\section{Declarations}

Ethic approval and consent to participate

Not applicable.

Consent for publication

Not applicable.

\section{Competing interests}

The authors declare that they have no competing interests.

\section{Author details}

${ }^{1}$ Mayo Clinic Medical Scientist Training Program, Mayo Clinic, Rochester, MN USA. ${ }^{2}$ Department of Biochemistry and Molecular Biology, Mayo Clinic, 200 First St SW, Rochester, MN 55905, USA. 
Received: 7 October 2020 Accepted: 15 March 2021

Published online: 25 March 2021

\section{References}

1. lizuka K, Machida T, Hirafuji M. Skeletal muscle is an endocrine organ. J Pharmacol Sci. 2014;125:125-31

2. Pedersen BK. Muscles and their myokines. J Exp Biol. 2011;214:337.

3. Hood DA, Irrcher I, Ljubicic V, Joseph A-M. Coordination of metabolic plasticity in skeletal muscle. J Exp Biol. 2006;209:2265

4. Lodi R, Schapira AHV, Manners D, et al. Abnormal in vivo skeletal muscle energy metabolism in Huntington's disease and dentatorubropallidoluysian atrophy. Ann Neurol. 2000;48:72-6.

5. Zhang L, Wang XH, Wang H, Du J, Mitch WE. Satellite cell dysfunction and impaired IGF-1 signaling cause CKD-induced muscle atrophy. J Am Soc Nephrol. 2010;21:419-27.

6. Julienne CM, Dumas J-F, Goupille C, et al. Cancer cachexia is associated with a decrease in skeletal muscle mitochondrial oxidative capacities without alteration of ATP production efficiency. J Cachexia Sarcopenia Muscle. 2012;3:265-75.

7. Tzika AA, Fontes-Oliveira CC, Shestov AA, et al. Skeletal muscle mitochondrial uncoupling in a murine cancer cachexia model. Int J Oncol. 2013:43:886-94.

8. Gouzi F, Blaquiere M, Catteau M, et al. Oxidative stress regulates autophagy in cultured muscle cells of patients with chronic obstructive pulmonary disease. J Cell Physiol. 2018;233:9629-39.

9. Wing SS, Goldberg AL. Glucocorticoids activate the ATP-ubiquitindependent proteolytic system in skeletal muscle during fasting. Am J Physiol Endocrinol Metabol. 1993;264:E668-76.

10. Schiaffino S, Dyar KA, Ciciliot S, Blaauw B, Sandri M. Mechanisms regulating skeletal muscle growth and atrophy. FEBS J. 2013;280:4294-314.

11. Tamilarasan KP, Temmel H, Das SK, et al. Skeletal muscle damage and impaired regeneration due to LPL-mediated lipotoxicity. Cell Death Dis. 2012:3:e354.

12. Järvinen $T A H$, Järvinen TLN, Kääriäinen $M$, Kalimo $H$, Järvinen M. Muscle injuries: biology and treatment. Am J Sports Med. 2005;33:745-64.

13. Mauro A. Satellite cell of skeletal muscle fibers. J Biophys Biochem Cytol. 1961;9:493-5.

14. Christov C, Chrétien F, Abou-Khalil R, et al. Muscle satellite cells and endothelial cells: close neighbors and privileged partners. Mol Biol Cell. 2007:18:1397-409.

15. Bischoff R. Regeneration of single skeletal muscle fibers in vitro. Anat Rec. 1975:182:215-35.

16. Ryall James G, Dell'Orso S, Derfoul A, et al. The NAD+-dependent sirt1 deacetylase translates a metabolic switch into regulatory epigenetics in skeletal muscle stem cells. Cell Stem Cell. 2015;16:171-83.

17. Wagatsuma A, Kotake N, Yamada S. Muscle regeneration occurs to coincide with mitochondrial biogenesis. Mol Cell Biochem. 2011;349:139-47.

18. Moyes CD, Mathieu-Costello OA, Tsuchiya N, Filburn C, Hansford RG. Mitochondrial biogenesis during cellular differentiation. Am J Physiol Cell Physiol. 1997;272:C1345-51.

19. Tajbakhsh S. Skeletal muscle stem cells in developmental versus regenerative myogenesis. J Intern Med. 2009;266:372-89.

20. Tang AH, Rando TA. Induction of autophagy supports the bioenergetic demands of quiescent muscle stem cell activation. EMBO J. 2014;33:2782-97.

21. Nagata Y, Partridge TA, Matsuda R, Zammit PS. Entry of muscle satellite cells into the cell cycle requires sphingolipid signaling. J Cell Biol. 2006;174:245-53

22. Mebarek S, Komati H, Naro F, et al. Inhibition of de novo ceramide synthesis upregulates phospholipase D and enhances myogenic differentiation. J Cell Sci. 2007;120:407-16.

23. Mead JR, Irvine SA, Ramji DP. Lipoprotein lipase: structure, function, regulation, and role in disease. J Mol Med. 2002;80:753-69.

24. Lee $S R$, Khamoui $A V$, Jo $E$, et al. Effects of chronic high-fat feeding on skeletal muscle mass and function in middle-aged mice. Aging Clin Exp Res. 2015:27:403-11.

25. D'Souza DM, Zhou S, Rebalka IA, et al. Decreased satellite cell number and function in humans and mice with type 1 diabetes is the result of altered notch signaling. Diabetes. 2016;65:3053.
26. Xu D, Jiang Z, Sun Z, et al. Mitochondrial dysfunction and inhibition of myoblast differentiation in mice with high-fat-diet-induced pre-diabetes. J Cell Physiol. 2019;234:7510-23.

27. Gulati AK, Swamy MS. Regeneration of skeletal muscle in streptozotocininduced diabetic rats. Anat Rec. 1991;229:298-304.

28. Vignaud A, Ramond F, Hourde C, Keller A, Butler-Browne G, Ferry A. Diabetes provides an unfavorable environment for muscle mass and function after muscle injury in mice. Pathobiology. 2007;74:291-300.

29. Roth SM, Martel GF, Ivey FM, et al. Skeletal muscle satellite cell populations in healthy young and older men and women. Anat Rec. 2000;260:351-8.

30. Zwetsloot KA, Childs TE, Gilpin LT, Booth FW. Non-passaged muscle precursor cells from 32-month old rat skeletal muscle have delayed proliferation and differentiation. Cell Prolif. 2013:46:45-57.

31. Shefer G, Van de Mark DP, Richardson JB, Yablonka-Reuveni Z. Satellite-cell pool size does matter: defining the myogenic potency of aging skeletal muscle. Dev Biol. 2006;294:50-66.

32. Day K, Shefer G, Shearer A, Yablonka-Reuveni Z. The depletion of skeletal muscle satellite cells with age is concomitant with reduced capacity of single progenitors to produce reserve progeny. Dev Biol. 2010;340:330-43.

33. Baraibar MA, Hyzewicz J, Rogowska-Wrzesinska A, et al. Impaired energy metabolism of senescent muscle satellite cells is associated with oxidative modifications of glycolytic enzymes. Aging. 2016;8:3375-89.

34. Sadeh M. Effects of aging on skeletal muscle regeneration. J Neurol Sci. 1988;87:67-74

35. Brooks SV, Faulkner JA. The magnitude of the initial injury induced by stretches of maximally activated muscle fibres of mice and rats increases in old age. J Physiol. 1996;497(Pt 2):573-80.

36. García-Prat L, Martínez-Vicente M, Perdiguero E, et al. Autophagy maintains stemness by preventing senescence. Nature. 2016:529:37-42.

37. Servián-Morilla E, Cabrera-Serrano M, Rivas-Infante E, et al. Altered myogenesis and premature senescence underlie human TRIM32-related myopathy. Acta Neuropathol Commun. 2019;7:30.

38. Kudryashova E, Kramerova I, Spencer MJ. Satellite cell senescence underlies myopathy in a mouse model of limb-girdle muscular dystrophy $2 \mathrm{H}$. J Clin Invest. 2012;122:1764-76.

39. Overå KS, Garcia-Garcia J, Bhujabal Z, et al. TRIM32, but not its muscular dystrophy-associated mutant, positively regulates and is targeted to autophagic degradation by p62/SQSTM1. Journal of Cell Science. 2019;132:jcs236596.

40. Dumont NA, Wang YX, von Maltzahn J, et al. Dystrophin expression in muscle stem cells regulates their polarity and asymmetric division. Nat Med. 2015;21:1455-63.

41. Ribeiro AF, Souza LS, Almeida CF, et al. Muscle satellite cells and impaired late stage regeneration in different murine models for muscular dystrophies. Sci Rep. 2019;9:11842.

42. Yablonka-Reuveni Z, Anderson JE. Satellite cells from dystrophic (mdx) mice display accelerated differentiation in primary cultures and in isolated myofibers. Dev Dyn. 2006;235:203-12.

43. Sacco A, Mourkioti F, Tran R, et al. Short telomeres and stem cell exhaustion model duchenne muscular dystrophy in $\mathrm{mdx} / \mathrm{mTR}$ mice. Cell. 2010;143:1059-71.

44. Webster C, Blau HM. Accelerated age-related decline in replicative lifespan of Duchenne muscular dystrophy myoblasts: implications for cell and gene therapy. Somat Cell Mol Genet. 1990;16:557-65.

45. Boldrin L, Zammit PS, Morgan JE. Satellite cells from dystrophic muscle retain regenerative capacity. Stem Cell Res. 2015;14:20-9.

46. Joseph J, Cho DS, Doles JD. Metabolomic analyses reveal extensive progenitor cell deficiencies in a mouse model of duchenne muscular dystrophy. Metabolites. 2018;8:61

47. Bell EL, Shine RW, Dwyer P, et al. PPAR $\delta$ modulation rescues mitochondrial fatty acid oxidation defects in the mdx model of muscular dystrophy. Mitochondrion. 2019:46:51-8.

48. Schaaf GJ, van Gestel TJM, Brusse E, et al. Lack of robust satellite cell activation and muscle regeneration during the progression of Pompe disease. Acta Neuropathol Commun. 2015;3:65.

49. Lagalice L, Pichon J, Gougeon E, et al. Satellite cells fail to contribute to muscle repair but are functional in Pompe disease (glycogenosis type II). Acta Neuropathol Commun. 2018;6:116. 
50. Schaaf GJ, van Gestel TJM, Groen SLM, et al. Satellite cells maintain regenerative capacity but fail to repair disease-associated muscle damage in mice with Pompe disease. Acta Neuropathol Commun. 2018;6:119.

51. Raben N, Schreiner C, Baum R, et al. Suppression of autophagy permits successful enzyme replacement therapy in a lysosomal storage disorder-murine Pompe disease. Autophagy. 2010;6:1078-89.

52. Ballabio A, Gieselmann V. Lysosomal disorders: from storage to cellular damage. Biochim Biophys Acta. 2009;1793:684-96.

53. Raben N, Shea L, Hill V, Plotz P. Monitoring autophagy in lysosomal storage disorders. Methods Enzymol. 2009;453:417-49.

54. Dupuis L, Oudart H, Rene F, Gonzalez de Aguilar JL, Loeffler JP. Evidence for defective energy homeostasis in amyotrophic lateral sclerosis: benefit of a high-energy diet in a transgenic mouse model. Proc Natl Acad Sci USA. 2004;101:11159-64.

55. Manzano R, Toivonen JM, Calvo AC, et al. Quantity and activation of myofiber-associated satellite cells in a mouse model of amyotrophic lateral sclerosis. Stem Cell Rev Rep. 2012;8:279-87.

56. Pradat PF, Barani A, Wanschitz J, et al. Abnormalities of satellite cells function in amyotrophic lateral sclerosis. Amyotroph Lateral Scler. 2011;12:264-71.

57. Gea J, Agustí A, Roca J. Pathophysiology of muscle dysfunction in COPD. J Appl Physiol. 2013;114:1222-34.

58. Lee $\mathrm{S}$, Tak E, Lee J, et al. Mitochondrial $\mathrm{H} 2 \mathrm{O} 2$ generated from electron transport chain complex I stimulates muscle differentiation. Cell Res. 2011;21:817-34.

59. Malinska D, Kudin AP, Bejtka M, Kunz WS. Changes in mitochondrial reactive oxygen species synthesis during differentiation of skeletal muscle cells. Mitochondrion. 2012;12:144-8.

60. L'honoré A, Commère P-H, Ouimette J-F, Montarras D, Drouin J, Buckingham M. Redox regulation by Pitx2 and Pitx3 is critical for fetal myogenesis. Dev Cell. 2014;29:392-405.

61. Catani MV, Savini I, Duranti G, et al. Nuclear factor kB and activating protein 1 are involved in differentiation-related resistance to oxidative stress in skeletal muscle cells. Free Radical Biol Med. 2004;37:1024-36.

62. Thériault M-E, Paré M-Ė, Maltais F, Debigaré R. Satellite cells senescence in limb muscle of severe patients with COPD. PLoS ONE. 2012;7:e39124.

63. Pomiès $P$, Rodriguez J, Blaquière $M$, et al. Reduced myotube diameter, atrophic signalling and elevated oxidative stress in cultured satellite cells from COPD patients. J Cell Mol Med. 2015;19:175-86.

64. Rocheteau P, Chatre L, Briand D, et al. Sepsis induces long-term metabolic and mitochondrial muscle stem cell dysfunction amenable by mesenchymal stem cell therapy. Nat Commun. 2015:6:10145.

65. Zou X, Meng J, Li L, et al. Acetoacetate accelerates muscle regeneration and ameliorates muscular dystrophy in mice. J Biol Chem. 2016;291:2181-95.

66. Carotenuto F, Costa A, Albertini MC, et al. Dietary flaxseed mitigates impaired skeletal muscle regeneration: in vivo, in vitro and in silico studies. Int J Med Sci. 2016;13:206-19.

67. He L, Tian X, Yan C, Liu D, Wang S, Han Y. Nicotine promotes the differentiation of $\mathrm{C} 2 \mathrm{C} 12$ myoblasts and improves skeletal muscle regeneration in obese mice. Biochem Biophys Res Commun. 2019;511:739-45.

68. Matsubara T, Urata M, Nakajima T, et al. Geranylgeraniol-induced myogenic differentiation of C2C12 cells. Vivo. 2018;32:1427-31.

69. Owens DJ, Sharples AP, Polydorou I, et al. A systems-based investigation into vitamin $D$ and skeletal muscle repair, regeneration, and hypertrophy. Am J Physiol Endocrinol Metab. 2015;309:E1019-31.

70. Haramizu S, Asano S, Butler DC, et al. Dietary resveratrol confers apoptotic resistance to oxidative stress in myoblasts. J Nutr Biochem. 2017;50:103-15.
71. Bakhtiari N, Hosseinkhani S, Soleimani M, et al. Short-term ursolic acid promotes skeletal muscle rejuvenation through enhancing of SIRT1 expression and satellite cells proliferation. Biomed Pharmacother. 2016;78:185-96.

72. Dogan SA, Cerutti R, Benincá C, et al. Perturbed redox signaling exacerbates a mitochondrial myopathy. Cell Metab. 2018;28(764-75):e5.

73. Brioche T, Kireev RA, Cuesta S, et al. Growth hormone replacement therapy prevents sarcopenia by a dual mechanism: improvement of protein balance and of antioxidant defenses. J Gerontol A Biol Sci Med Sci. 2014;69:1186-98.

74. Widdowson WM, Gibney J. The effect of growth hormone replacement on exercise capacity in patients with GH deficiency: a metaanalysis. J Clin Endocrinol Metab. 2008;93:4413-7.

75. Widdowson WM, Gibney J. The effect of growth hormone $(\mathrm{GH})$ replacement on muscle strength in patients with $\mathrm{GH}$-deficiency: a meta-analysis. Clin Endocrinol (Oxf). 2010;72:787-92.

76. Velders M, Schleipen B, Fritzemeier KH, Zierau O, Diel P. Selective estrogen receptor- $\beta$ activation stimulates skeletal muscle growth and regeneration. FASEB J. 2012;26:1909-20.

77. Sinha-Hikim I, Roth SM, Lee MI, Bhasin S. Testosterone-induced muscle hypertrophy is associated with an increase in satellite cell number in healthy, young men. Am J Physiol Endocrinol Metabol. 2003;285:E197-205

78. Cerletti M, Jang Young C, Finley Lydia WS, Haigis Marcia C, Wagers AJ. Short-term calorie restriction enhances skeletal muscle stem cell function. Cell Stem Cell. 2012;10:515-9.

79. Boldrin $L$, Ross JA, Whitmore $C$, et al. The effect of calorie restriction on mouse skeletal muscle is sex, strain and time-dependent. Sci Rep. 2017;7:5160.

80. Horie M, Enomoto M, Shimoda M, Okawa A, Miyakawa S, Yagishita K. Enhancement of satellite cell differentiation and functional recovery in injured skeletal muscle by hyperbaric oxygen treatment. J Appl Physiol. 1985:2014(116):149-55.

81. Oyaizu T, Enomoto M, Yamamoto N, et al. Hyperbaric oxygen reduces inflammation, oxygenates injured muscle, and regenerates skeletal muscle via macrophage and satellite cell activation. Sci Rep. 2018;8:1288.

82. Yamamoto $\mathrm{N}$, Oyaizu T, Enomoto M, et al. VEGF and bFGF induction by nitric oxide is associated with hyperbaric oxygen-induced angiogenesis and muscle regeneration. Sci Rep. 2020;10:2744.

83. Fischer KD, Heitzman JA, Townsend D. Hyperbaric therapy provides no benefit for skeletal muscle and respiratory function and accelerates cardiac injury in mdx mice. Sci Rep. 2019;9:12306.

84. Maeda Y, Yonemochi Y, Nakajyo Y, Hidaka H, Ikeda T, Ando Y. CXCL12 and osteopontin from bone marrow-derived mesenchymal stromal cells improve muscle regeneration. Sci Rep. 2017;7:3305.

85. Nakamura Y, Miyaki S, Ishitobi H, et al. Mesenchymal-stem-cellderived exosomes accelerate skeletal muscle regeneration. FEBS Lett. 2015;589:1257-65.

86. Fu X, Zhu M, Zhang S, Foretz M, Viollet B, Du M. Obesity impairs skeletal muscle regeneration through inhibition of AMPK. Diabetes. 2016:65:188-200.

\section{Publisher's Note}

Springer Nature remains neutral with regard to jurisdictional claims in published maps and institutional affiliations. 